\title{
MALIGNANT TUMOURS OF THE TESTIS
}

\author{
By M. D. SNelling, F.R.C.S., M.R.C.P., D.M.R., and D. M. T. Cones, D.M.R.T. \\ From the Meyerstein Institute of Radiotherapy, Middlesex Hospital
}

Malignant testicular tumours fall into two main groups; seminoma, otherwise known as carcinoma or spermatocytoma, and teratoma, incorporating the more malignant and rapidly growing chorionepithelioma. Sertoli cell tumours are rare and interstitial cell tumours are more commonly benign; secondary malignant tumours are rare, there being less than 50 reported cases in the literature. ${ }^{9}$ We are most concerned here with seminoma and teratoma, and this article is based upon 166 cases treated and followed up at the Middlesex Hospital between 1929 and 1951. Of these, 67 per cent. were seminoma and 33 per cent. teratoma. This figure corresponds exactly with the series reported by Gordon-Taylor and Wyndham, ${ }^{7}$ and although a number of our cases are included in their series they also included cases from other hospitals in London, the South-East of England and Australia. The percentage of seminoma is rather higher than is usually given, figures varying from 59 per cent. to 65 per cent. having been previously reported.

It is not within the scope of this article to comment on the difference of opinion regarding the histogenesis of seminoma, nor would we presume to do so. Ewing ${ }^{6}$ has stated that seminoma does not arise from seminal epithelium, but is an embryonal carcinoma arising in a teratoma. Willis ${ }^{15}$ is equally definite in his theory that seminoma arises from seminal epithelium and is a separate entity from teratoma, and his arguments are now widely accepted on both sides of the Atlantic.

\section{Morbid Anatomy}

The cut section of a seminoma of the testis shows a soft opaque tumour, white or yellowish in colour, invading and destroying the body of the testis. A thin layer of testicular tissue may be recognizable surrounding the tumour. The tumour itself is structureless and homogeneous, sometimes with areas of haemorrhage and necrosis; fibrous trabeculae may sometimes be present giving a lobulated appearance (Fig. I).

Histologically, diffuse masses of large polygonal cells with a clear or finely granular cytoplasm are

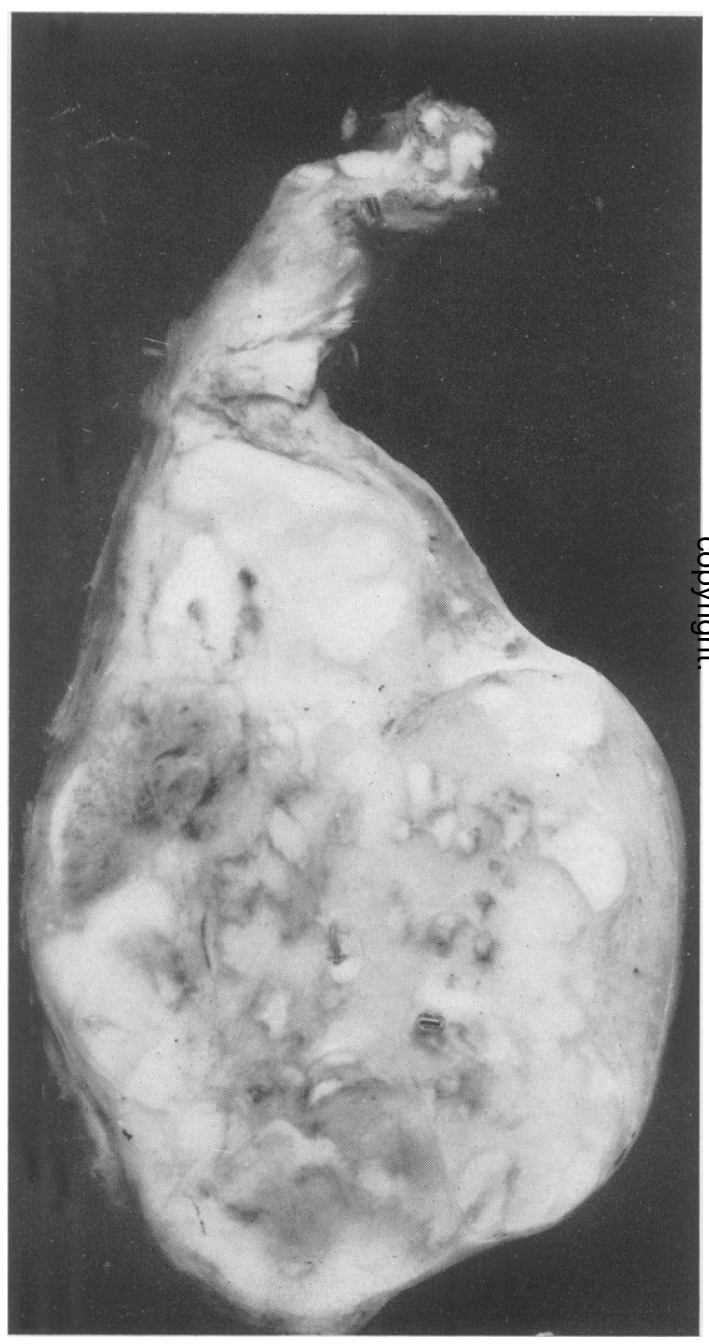

FIG. I. Naked eye appearance of a seminoma.

seen, with a well-marked cell boundary and small, somewhat rounded, hyperchromatic nuclei with prominent acidophile nucleoli. These cells resemble spermatocytes. In some cases the cells are small with large nuclei resembling spermatoblasts, and may give the appearance of lymphosarcoma. 


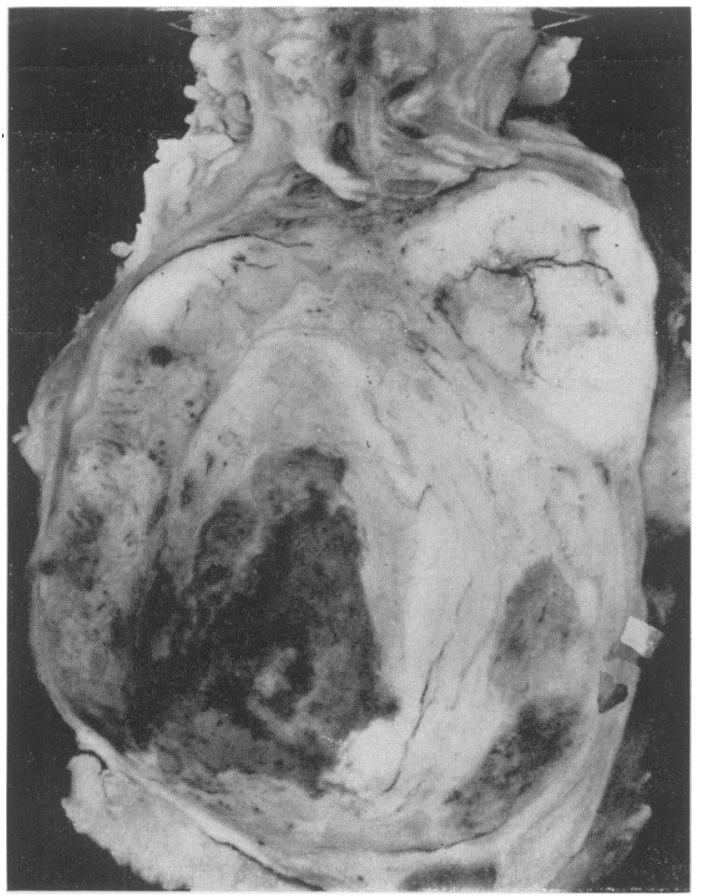

Fig. 2.-Naked eye appearance of a malignant teratoma.

The supporting stroma is usually scanty, or at the most it may be composed of delicate connective tissue, with some degree of lymphocytic infiltration or even lymphoid follicles which may give a lobulated structure.

A malignant teratoma on cut section shows partial or complete replacement of the testis with new growth, with sometimes extensive areas of haemorrhage and necrosis (Fig. 2). There is usually a sharply defined capsule outside which the testicular tissue is stretched in a thin layer. Sometimes a lobulated cystic appearance predominates, known surgically as fibrocystic disease (Fig. 3), with intervening solid areas showing translucent nodules of cartilage, muscle, fat or areas of haemorrhage.

Histologically a teratoma is derived from all three germinal layers but the cells have no adult anatomical arrangement. Numerous tissues, mainly of embryonal type, may be identified, and there is a marked tendency for the derivatives of one germinal layer to predominate to the exclusion of others and develop malignant characteristics. Cartilage, bone, plain muscle and tubules lined by squamous and various types of columnar epithelium may all be seen, but often it is the embryonal elements of less easily recognizable tissue that form the malignant element. Chorion-

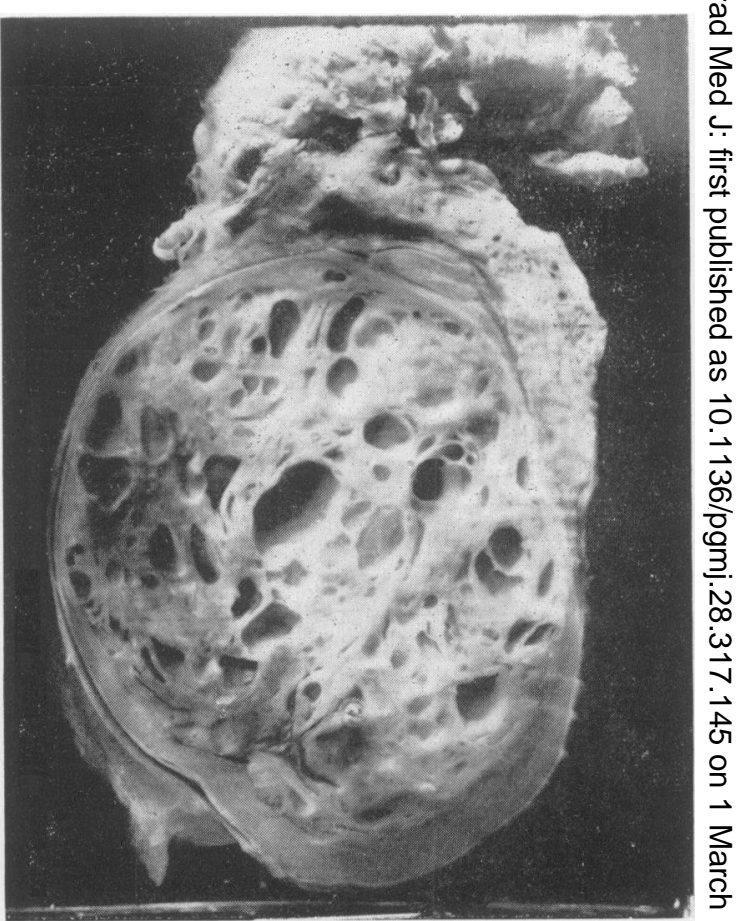

○े

FIG. 3.-Cystic teratoma or fibrocystic disease of क्षैట़ testis.

epithelioma (Fig. 4) has also been described as separate entity, but it is merely the proliferation of the chorionic elements of a malignant teratoms and shows a histological structure identical with the uterine tumour of the same name.

Anatomically the main consideration in the treat ment of malignant disease of the testis is that of lymphatic drainage. Patients may attend fok advice with diverse symptoms other than swelling of the testis. Abdominal pain, the finding of $\frac{3}{8}$. lump in the abdomen, or symptoms of cough? dyspnoea or even haemoptysis may cause them to. attend for the first time, and the presence of 25 testicular tumour may be demonstrated only or routine examination. Fig. 5 is the skiagram of the chest of a man who attended hospital complaining of frequent small haemoptyses; he also had a mass in the left side of the abdomen. A small nodules was found in the left testis and positive Friedman Ascheim-Zondek and follicle stimulating hor+t mone reactions in his urine led to a clinical $\operatorname{diag}_{\sigma}^{\omega}$ nosis of teratoma of the testis with multiple metastases. The presence of rounded opacities ing the lung fields in a man below the age of 452 should always suggest new growth of the testis as the likely diagnosis, even if such a tumour canno be demonstrated clinically.

Fig. 6 is a diagram showing the lymphati市 


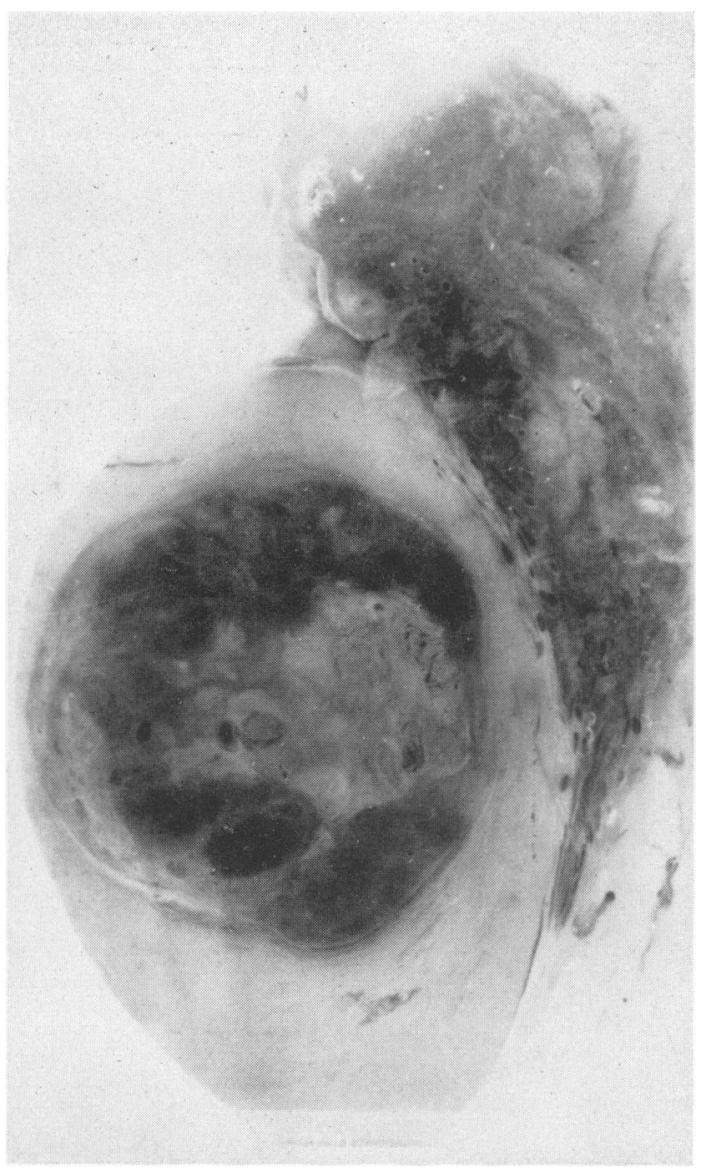

FIG. 4.-Naked eye appearance of a chorionepithelioma.

drainage of the testis. Lymphatics from the testis arise in a superficial plexus under the tunica vaginalis and a deep plexus in the substance of the testis and epididymis. 'The afferent lymphatic trunks ascend in the spermatic cord. For this reason orchidectomy should always be performed through an inguinal incision and the cord divided at the internal ring, thus providing for removal of the whole of the primary growth and proximal lymphatic drainage. 'The afferent trunks end in the lateral aortic and pre-aortic lymph glands without interruption in their course, and the two groups of glands are known collectively as the para-aortic glands. Retrograde spread can occur to the common and internal iliac glands. When invasion of the scrotal tissue has occurred, lymph node metastases may be found in the superficial inguinal group.

Involvement of the mediastinal glands can occur radiologically without demonstrable involvement

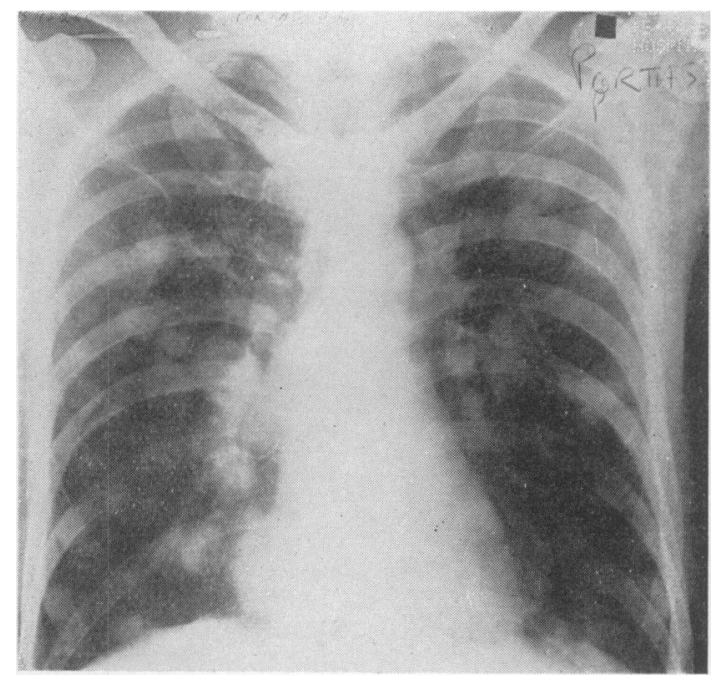

FIG. 5.-Multiple secondary deposits in the chest from a chorionepithelioma.

of glands inside the abdomen. However, mediastinal involvement usually follows involvement of the para-aortic group. Fig. 7 shows mediastinal glandular enlargement from a case of seminoma testis. Fig. 8 is the same patient after X-ray therapy and shows the marked radio-sensitivity of the growth. Enlargement of Virchow's gland may be found without clinical manifestations of other glandular metastases. Prosser ${ }^{14}$ in a review of 74 cases with metastases at the Westminster Hospital, gave a percentage incidence of 53 per cent. paraaortic involvement, I4 per cent. supraclavicular glands and 13 per cent. inguinal glands, while only 5 per cent. of his cases showed mediastinal involvement. His figures show an approximately equal distribution between seminoma and teratoma, except that supraclavicular metastases werc ten times as common in teratoma as in seminoma.

Blood borne metastases are more common in teratoma than in seminoma. Lungs, liver, bones and brain are most commonly involved and in that order of frequency. Fig. 9a shows a peculiar type of metastasis from a seminoma-a mass, probably from the liver, eroding the oesophagus just above the cardia and causing symptoms of dysphagia and several copious haematemeses. This proved, as usual, most radiosensitive and Fig. $9 b$ shows the appearances following treatment. Fig. Io shows the typical osteolytic deposits which occur in skeletal metastases from seminoma. In this patient a deposit in the fifth metatarsal bone was the first sign of spread of the disease beyond the testis. 


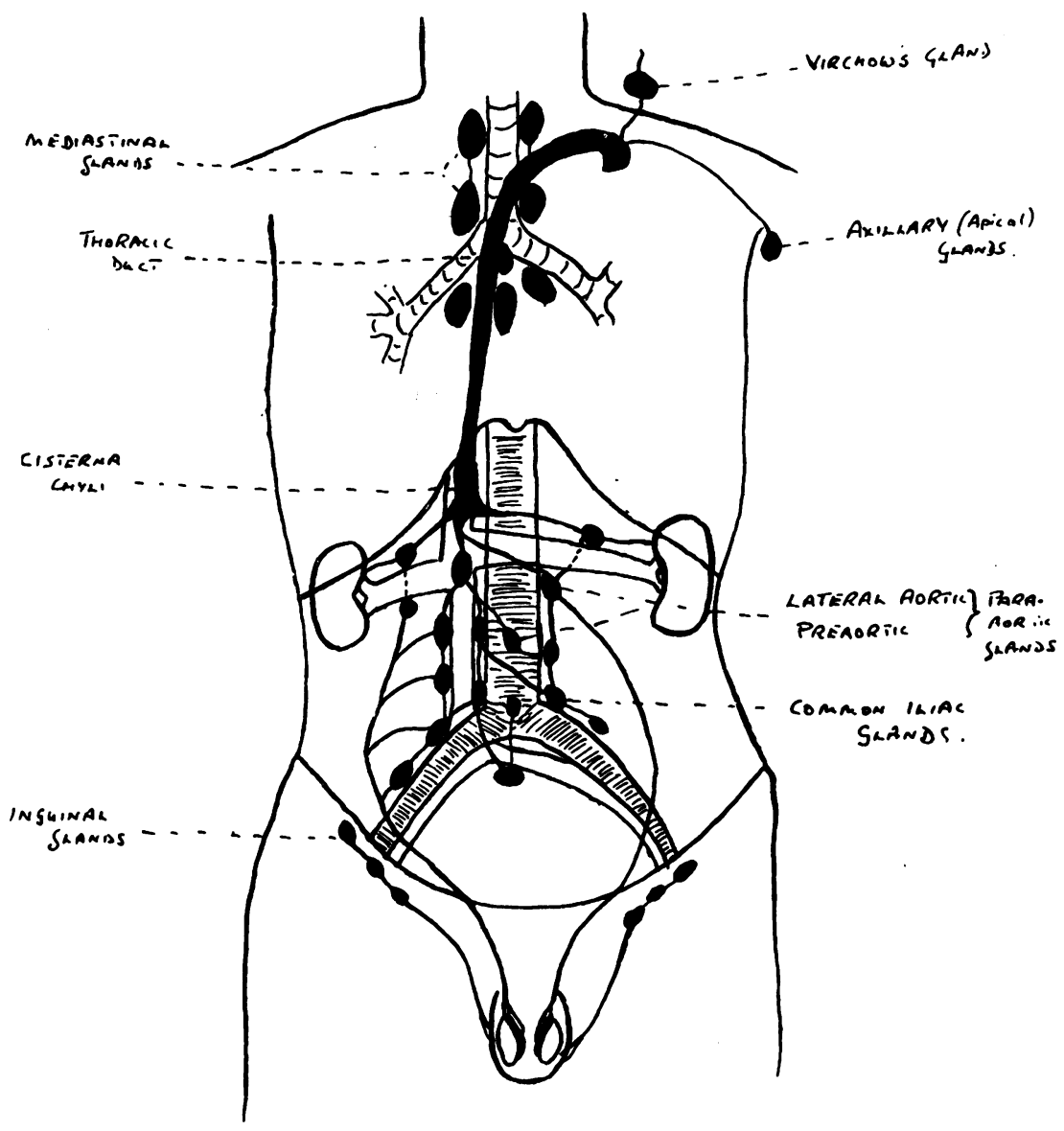

Fig. 6.-Diagramatic representation of testicular lymph drainage.

\section{Biochemistry}

The presence of gonadotropic hormone in the urine of patients suffering from testicular tumours may be of some value in diagnosis and in determining prognosis; the absence of such hormone is of no clinical or prognostic consequence. The Ascheim-Zondek reaction is that most commonly used, and is based on the presence in the urine of excessive amounts of chorionic gonadotropin, which will produce blood spots and luteinization in the ovaries when injected into immature mice; this chorionic gonadotropin (possibly after stimulating the pituitary to produce follicle stimulating hormone) then acts on the stimulated ovaries to produce these above changes. Chorionic gonadotropin is produced by the normal placenta and also by malignant teratoma and chorionic epithelioma. A positive reaction is most commonly given by highly undifferentiated teratomatous tumours and is not usually positive in those which show well-marked tubule formation with cartilage, bone, muscle ang other adult features. The Ascheim-Zondek test ing such conditions is often positive with high dilution of the urine and the concentration of chorionio gonadotropin may be roughly estimated by finds ing the greatest dilution of the urine that will give 8 a positive reaction. Regular tests during treatment are of value in estimating progress.

The presence and persistence of a positivi Ascheim-Zondek reaction following orchidectom 9 for teratoma is strong presumptive evidence og metastases, even though these may not be clinicallfo demonstrable. A positive reaction may be of utmost value in the diagnosis of abdomina testicular neoplasm in those cases of abdomina testis, or where orchidocleisis has been performed? The Ascheim-Zondek reaction will become negav tive following orchidectomy in the absence of metastases and often following irradiation of metastases, but it must be emphasized that $\vec{g}$ 


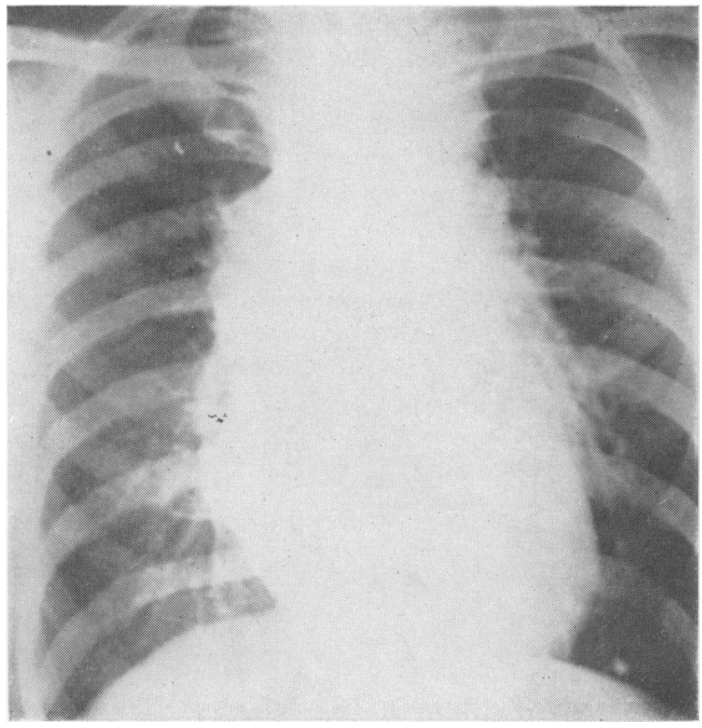

Fig. 7.-Mediastinal glandular enlargement from seminoma testis.

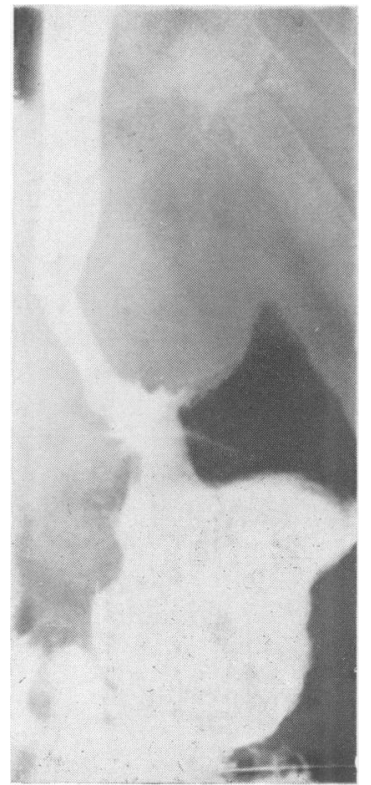

FIG. 9a.-Metastatic mass from a seminoma erocling the nesophagus.

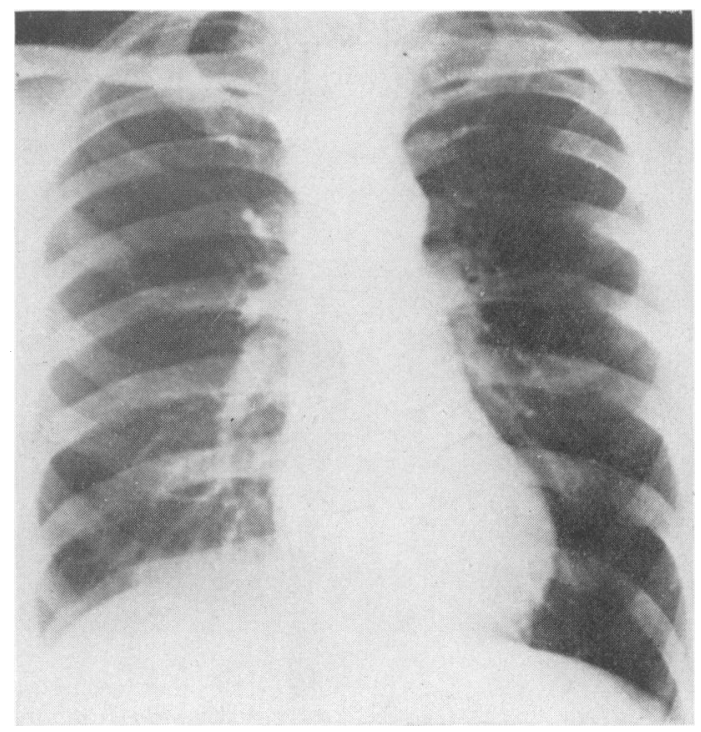

Fig. 8.- Same patient as Fig. 7 following irradiation of mediastinal glands.
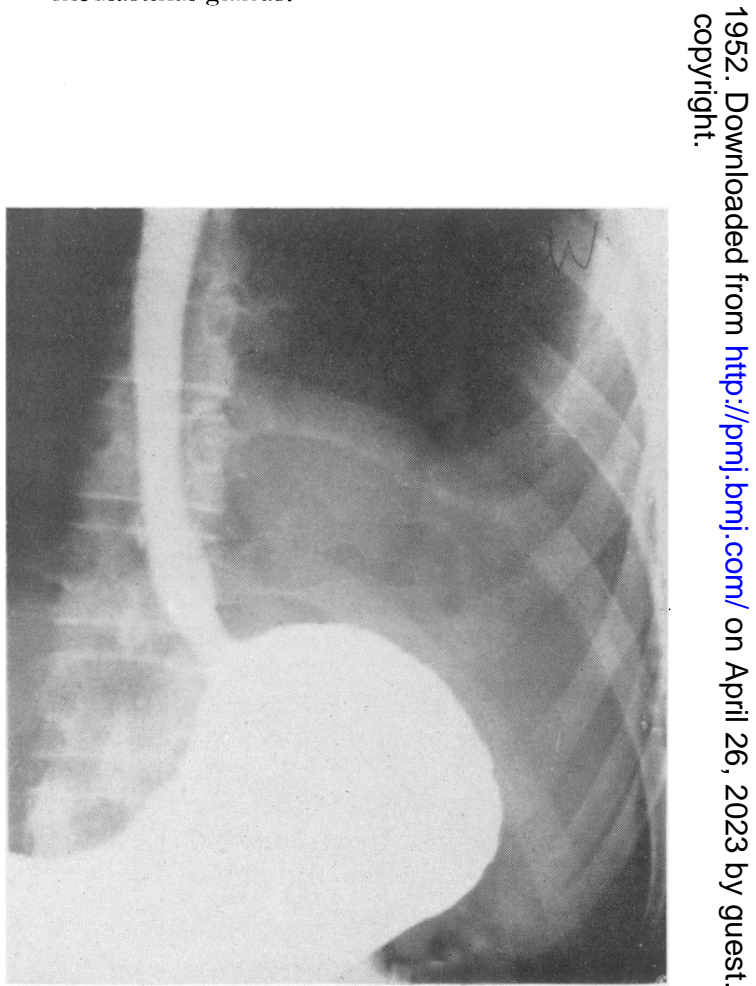

FIG. 9b.-From the same patient as Fig. 9a, following irradiation. 


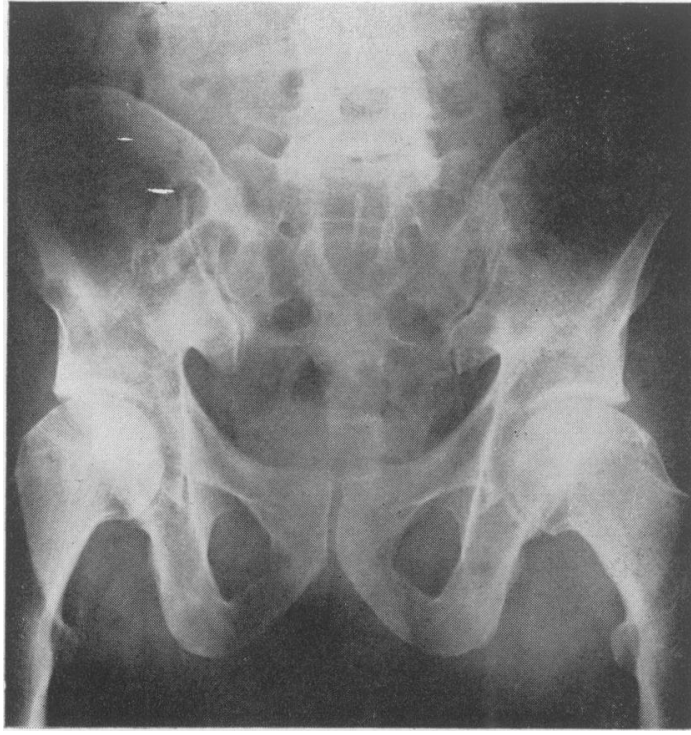

FIG. I0.-Osteolytic secondary deposit from a seminoma in right half of sacrum, with further deposit and early collapse of the 5 th lumbar vertebra.

negative reaction is often given even in the presence of multiple secondary deposits. The test should therefore not be used as a sole guide to prognosis but merely as additional evidence, and should certainly not supercede regular clinical and radiological examinations.

In seminoma the Ascheim-Zondek reaction is almost always negative. Gordon-Taylor ${ }^{1-}$ has summarized the work of various authors who have differentiated the types of gonadotropic hormone excreted in the urine and have made a distinction between pituitary gonadotropin and chorionic gonadtropin, the former being follicle stimulating hormone. The importance of this differentiation is based on the increased excretion of follicle stimulating hormone by patients with seminoma which prove markedly radiosensitive, and so a more favourable prognosis is to be expected. 'This hormone can be estimated quantatively by a tedious technique based on the increase in the uterine weight of immature virgin mice or rats, and is not performed as a routine in all cases of seminoma. However, if an Ascheim-Zondek test is performed, a qualitative positive result for excessive follicle stimulating hormone can sometimes be detected.

\section{Clinical Features}

\section{Aetiology}

Age Incidence. Malignant tumours of the testis occur at a younger age than do most forms of malignant disease. Although occurring rarely in children and aged patients the incidence of teratoma and seminoma is highest between the ages of 20 and 45 years. Teratoma occurs more commonly in younger patients than does.seminoma, and while the average age of patients: suffering from the former tumour is usually given as 28 or 30 years, that of patients with seminome is in the region of 40 years $\left({ }^{5,8}\right)$. In a series of I 12 cases of seminoma and 54 cases of teratoma attending the Middlesex Hospital for treatment $O \mathbb{Q}$ follow-up pirposes between 1929 and 195 I, it waô found that the great majority of cases of teratoma occurred between the ages of 20 and 35 years; while seminoma was most common between $3 \vec{\omega}$ and 40 years (Fig. I I ).

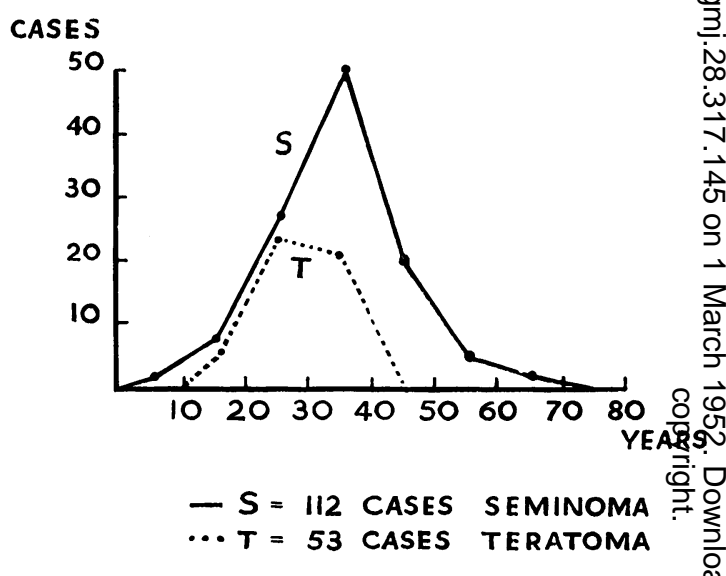

FIG. 1 1.- Graph showing the differing age distribution of seminoma and teratoma.

\section{Predisposing C'auses}

The relation between injury and malignan change is of great importance. In most forms of malignant disease the part played by trauma is open to question, but its high incidence in testicu $\frac{5}{3}$ lar tumours suggest that in this case at least it is of definite importance. 'The history obtained from? the patient in these cases is usually quite definite since, whereas slight injury to most parts of ther body is commonly disregarded by the patient or remembered at best imperfectly, injury to the testis is well remembered because of the associated intense pain, the often conspicuous bruising and what the patient considers to be the probable con sequences. For the same reasons the injury is often reported and can therefore be confirmeck from medical records. After indefinite injuries 0 many years old, have been discounted, the in cidence of trauma in these case histories is still so high as to make it appear that there is a definite relationship between an injury and the develop-西 ment of this tumour. 
'T'ABI.L: 1

Interval. Between Trauma and Appearance of Testicular Swelling

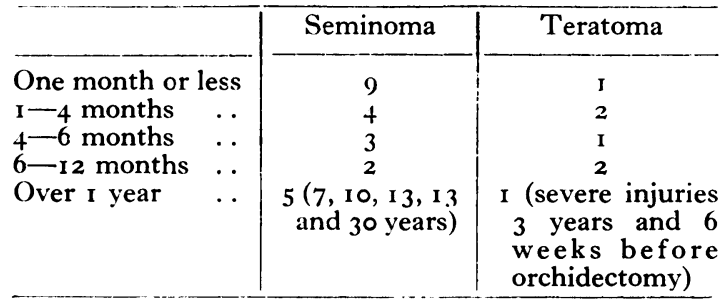

Although Myata ${ }^{13}$ reported a history of injury in nearly one half of his cases, the most common figure in the literature on the subject varies between 10 and 30 per cent. ${ }^{8,11,1: 3}$ In this series of patients treated or 'followed' at the Middlesex Hospital a definite history of injury was obtained in 18 per cent. of 167 cases of testicular tumours (20 per cent. seminoma and 13.5 per cent. teratoma).

The time relationship between the injury and the development of the tumour varies between a few weeks and several years. Although the latter type of case cannot be used as convincing evidence, as most adult males have some history of trauma, the former is often so dramatic as to leave little doubt in the mind of the observer as to the relation between the two events. In some of these cases the post-traumatic bruising and swelling had not disappeared before a second increase in size of the testis indicated the development of a-usually rapidly growing-tumour, while in two cases in this small series orchidectomy was performed on a diagnosis of injury, and the seminoma found only on subsequent pathological examination.

Of the 30 patients in this series giving a precise history of injury, 24 dated its occurrence no more than one year before the appearance of the tumour ('Table I).

\section{Development of Malignant Disease in an Un- descended Testis}

There appears to be no doubt that there is an unusually high incidence of malignant tumours among patients suffering from maldescent of the testis, and that this development cannot be avoided by orchidopexy or replacement of the testis in the abdomen. The incidence of maldescent in the adult population is given as approximately 0.23 per cent. ${ }^{4}$ and yet its incidence among patients suffering from malignant testicular tumours has been reported by several writers as between ro and 13.5 per cent. ${ }^{7}, 12,10,15,2$. In the present series there was an incidence of 10.3 per cent.; a seminoma developed in eight cases of patients in whom the testis had remained in the inguinal canal, and also in three patients in whom orchidopexy had been performed, and in one in whom the testis had been replaced in the abdomen. The age incidence did not differ from that in the remaining patients in this series and although the prognosis is often stated to be worse in these patients, there was no demonstrable difference in the results of treatment ('Table 2).

Although cases have been recorded where a tumour developed shortly after orchidopexy, it appears to be more common for the malignant change to develop some considerable time after the operation. In the three patients in the present series, orchidopexy had been performed 5, 12 and 19 years before the appearance of the seminoma. The last two cases are of especial interest since they were identical twins; the first was treated by orchidectomy and radiotherapy in $194^{2}$, and again by radiotherapy in 1943 and 1944 when he developed first abdominal and then pulmonary metastases. In I95I, when he was well and without clinical or radiological evidence of disease, his twin was admitted for treatment of the same condition. Orchidocleisis, or replacement of the testis in the abdomen, also does not preclude the development of a neoplasm? ${ }^{7}$. This operation had been performed on one patient in this series at thes age of 39 years, but six years later laparotomy for an abdominal mass revealed the presence of a seminoma with involvement of the iliac lymph glands.

\section{Other Factors}

Venereal disease has been held to be of importance in the development of these tumours and is sometimes said to predispose to a high degree of malignancy. This appears to be open to question, and in this series only one patient had co-existent gonococcal infection. The chief importance of the infection lies in the increased difficulty in diagnosis and consequent delay in instituting treatment.

\section{Clinical Signs and Symptoms \\ First Symptom}

Swelling of Testis. Testicular tumours present classically as slow growing and painless swellings associated with an early loss of testicular sensation. The onset is insidious and since there is nothing to alarm the patient he too often delays seeking advice until the disease is already widespread. As with all forms of malignant disease, the activity of similar tumours varies greatly in different patients, and while some may delay for many months-or even years-before attending for treatment and yet show no signs of metastases, others die of widespread disease within a few 
'I'ABI.1: 2

Results of the Treatment of Seminoma Developing in Undescended Testicle (Inguinal.)

\begin{tabular}{|c|c|c|c|c|c|c|c|}
\hline & \multicolumn{3}{|c|}{ Year treated } & \multicolumn{2}{|r|}{ Age } & Stage & Result \\
\hline I 931 & $\cdots$ & . & . & . & $3^{8}$ & I & Alive and well 20 years. \\
\hline 1934 & $\ldots$ & . & $\ldots$ & . & 45 & I & Alive and well is years. \\
\hline 1939 & . & $\cdots$ & . & . & 36 & I & Alive and well i 2 years. \\
\hline 1944 & . & $\cdots$ & . & . & 49 & I & No recurrence 5 years-died other causes. \\
\hline 1945 & . & . & . & . & $3 \mathrm{I}$ & I & Alive and well 6 years. \\
\hline I 947 & . & $\cdots$ & . & . & 35 & $\mathbf{I}$ & Alive and well 4 years. \\
\hline 1948 & $\cdots$ & . & $\cdots$ & . & 35 & 2 & Alive and well 3 years. \\
\hline
\end{tabular}

Results in Cases Previously Trfated for Maidescent

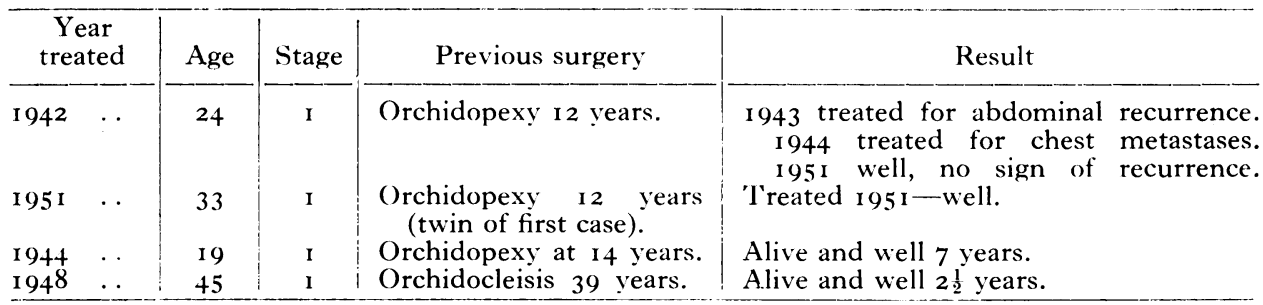

weeks of the appearance of the first symptoms. In these very acute forms of the disease the primary tumour may remain very small and the symptoms for which the patient seeks advice are those caused by metastases.

In this series of 167 cases on which this paper is based, $15^{6}$ had noticed a swelling of the testis. 'This swelling was due to the tumour in 143 cases, while in the other 13 its presence was masked by a hydrocele or haematocoele (Table 3 ). Ten of these patients only complained of testicular pain, but five complained of abdominal or lumbar pain caused by the involvement of the aortic glands.

Eleven patients had not noticed the testicular swelling. In two the tumour was found on routine medical examination; of the other nine, four were complaining of lumbar or abdominal pain due to abdominal glands, three of persistent cough due to pulmonary metastases and the remaining two in whom the disease was also widespread were complaining of loss of weight.

Hypertrophy of the breasts may occur if there is a rise in the hormone content of the blood, and is of value in confirming the diagnosis.

\section{Relation of Duration of Symptoms to Prognosis}

As in other forms of malignant disease there is no direct relation between the time that the patient has delayed before seeking advice and the results of treatment-indeed a first glance at statistics sometimes suggests that a short history often entails the worse prognosis. If a patient experiences no real discomfort he will often delay for many months or even years before asking for treatment-four of our patients with seminoma had been conscious of tumours for $3, \mathrm{I} 0, \mathrm{I} \overrightarrow{\mathrm{k}}$ and 30 years respectively, while two cases ow teratoma had similarly ignored their symptoms for 10 and 30 years before an acceleration in the rate of growth brought them to the out-pationgr

Tabile 3

Finst Symptoms in i67 Cases of Testicular Tumou丣

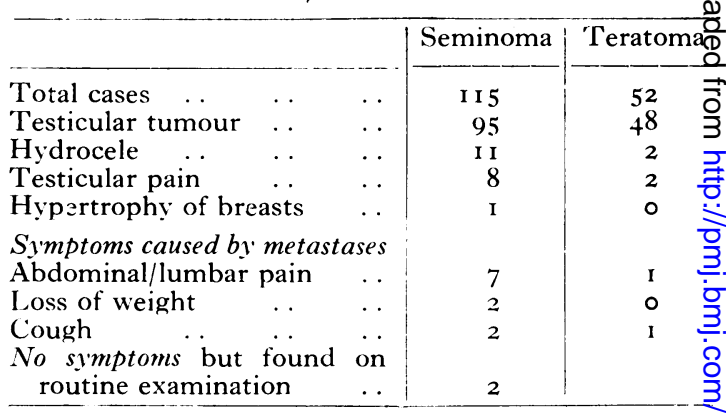

department. In such cases the very fact of surs vival indicates a low malignancy in the tumour an a consequent delay in metastasis. Other patients attended within a few weeks of the appearance of the swelling and already there was found to be involvement of the abdominal glands or lungs. Table 4 shows the relation of the duration of the symptoms (where this was known exactly) to the stage of the disease when the patient was first seerio and it is clear that, as one would expect, the incidence of advanced disease does not rise with the increased duration of symptoms.

Table 5 shows the results of treatment related 
to the duration of symptoms, and it is clear that there is no relation between the two. As we would expect, the prognosis is related to the stage of the disease and, if taken as a group, Stage I cases will do equally well whatever the length of history. With a greater number of cases it would be possible to break the series down further, and one might then expect to find that in the same stage early metastasis gave a worse prognosis than late metastasis since it indicates a higher grade of malignancy. ${ }^{1}$

\section{Clinical Signs and Diagnosis}

In most cases the predominating sign is the presence of a swelling in the testicle which is often (although not always) painless and associated with loss of testicular sensation. In some cases, however, this tumour may be very small, while the more obvious signs are due to the presence of glandular or blood stream metastases.

\section{Primary Tumour}

The most important sign is the presence of the tumour, limited at first to the testis, although later perhaps involving the epididymis or skin. The presence of this tumour may be masked by the development of a hydrocoele or of a haematocoele -always a suspicious sign. The local condition is often unmistakable, while the presence of metastases, or of breast changes or a positive Ascheim-Zondek reaction will confirm the diagnosis; a negative reaction is, however, of no diagnostic importance.

\section{Differential Diagnosis of Primary Tumour}

I. Trauma. We have already seen that a history of trauma is present in 10 to 20 per cent. of cases of testicular tumour, and that this tumour may develop before the signs of injury have subsided. In such cases the neoplasm is often of the highest malignancy and unless diagnosed early treatment may prove ineffective. The possibility of malignant disease must always be borne in mind in cases of trauma where pain or swelling persist longer than is expected. In two cases in this series orchidectomy was performed for post-traumatic swelling and tenderness, and the testis was found to contain a rapidly growing neoplasm.

2. Infection. (a) Acute Infection. Usually gonococcal. In most cases the site of the infection, the signs of inflammation and the evidence of infection elsewhere distinguish the two conditions. It must, however, be remembered that rarely a rapidly growing tumour will simulate an acute infection, and that again the two conditions may co-exist.

(b) Chronic Infection. Tuberculous and chronic pyogenic infection are distinguished by the pre-
TABLE 4

Duration of Symptoms Before Seeking Advice and Stage When First SeEN

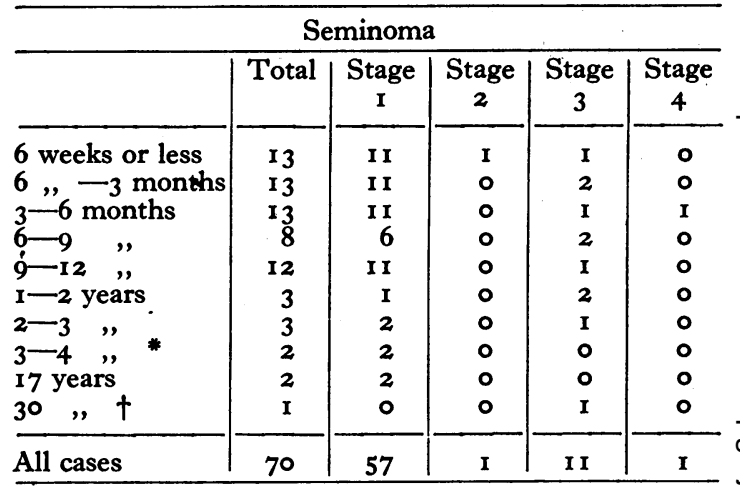

\begin{tabular}{|c|c|c|c|c|}
\hline \multicolumn{5}{|c|}{ Teratoma } \\
\hline & Total & Stage $\mathbf{I}$ & Stage 3 & Stage 4 \\
\hline $\begin{array}{l}6 \text { weeks or less } \\
6 \text { " } 3 \text { months } \\
3-6 \text { months } \\
6-9 \text { " } \\
9 \text { months-1 year } \\
2-3 \text { years } \\
3 \text { yeass } \\
4 \text { "Few } \ddagger \\
\text { years' }\end{array}$ & $\begin{array}{r}10 \\
5 \\
2 \\
2 \\
2 \\
2 \\
1 \\
1 \\
1\end{array}$ & $\begin{array}{l}8 \\
3 \\
0 \\
2 \\
2 \\
2 \\
0 \\
1 \\
0\end{array}$ & $\begin{array}{l}\mathbf{I} \\
\mathbf{I} \\
\mathbf{I} \\
0 \\
0 \\
\mathbf{0} \\
\mathbf{I} \\
\mathbf{0} \\
\mathbf{I}\end{array}$ & $\begin{array}{l}\mathbf{I} \\
\mathbf{I} \\
\mathbf{I} \\
0 \\
0 \\
0 \\
0 \\
0 \\
0\end{array}$ \\
\hline All cases & 26 & 18 & 5 & 3 \\
\hline
\end{tabular}

* I case, rapid increase during last 9 months. + Further increase in size during last 2 years. $\ddagger$ Further increase in last 2 months.

TABLE 5

Survival Rate Related to Duration of Symptoms Before TREATMENT

\begin{tabular}{|c|c|c|c|c|}
\hline \multicolumn{5}{|c|}{ SEMINOMA (cases treated 1929-46) } \\
\hline & $\begin{array}{c}\text { All } \\
\text { cases }\end{array}$ & $\begin{array}{c}5 \text {-year } \\
\text { survival }\end{array}$ & $\underset{I}{\text { Stage }}$ & $\begin{array}{l}\text { Stage I } \\
\text { (5-year } \\
\text { survival) }\end{array}$ \\
\hline $\begin{array}{l}6 \text { weeks or less } \\
6 \text { weeks-3 months } \\
3 \text { months-6 " } 6 \\
6 \text { " - } 7 \text { - } \\
9 \text { " year } \\
\text { Over I year }\end{array}$ & $\begin{array}{r}12 \\
8 \\
9 \\
4 \\
7 \\
4\end{array}$ & $\begin{array}{r}10 \\
7 \\
7 \\
2 \\
4 \\
3\end{array}$ & $\begin{array}{r}10 \\
7 \\
7 \\
3 \\
6 \\
3\end{array}$ & $\begin{array}{l}9 \\
7 \\
6 \\
2 \\
3 \\
3\end{array}$ \\
\hline " & 44 & 33 & 36 & 30 \\
\hline
\end{tabular}

Teratoma (cases treated 1929-46)

\begin{tabular}{l|c|c|c|c}
\hline & $\begin{array}{c}\text { All } \\
\text { cases }\end{array}$ & $\begin{array}{c}\text { 5-year } \\
\text { survival }\end{array}$ & $\begin{array}{c}\text { Stage } \\
\text { I }\end{array}$ & $\begin{array}{c}\text { Stage I } \\
\text { (5-year } \\
\text { survival) }\end{array}$ \\
\hline 6 weeks or less & 6 & 4 & 6 & 4 \\
6 weeks-3 months & 4 & 0 & 2 & 0 \\
$3-6$ months & 2 & 0 & 0 & 0 \\
$6-9 . "$ & 2 & 1 & 1 & 1 \\
9-12 " & 1 & 1 & 1 & 1 \\
Over 1 year & 5 & 1 & 3 & 1 \\
\hline
\end{tabular}


sence of epididymitis and other evidence of infection, although in some cases nodules due to a neoplasm may present a very similar appearance.

(c) Syphilis causes a painless, although usually nodular, enlargement of the testicle which may be indistinguishable from an early neoplasm. A negative Wasserman reaction is of importance in diagnosis-a positive one may be misleading.

\section{Clinical Signs Caused by Metastases}

I. General Signs. Anorexia, loss of weight, etc., appear only when the disease is far advanced and multiple metastases are already present. They are, therefore, of little value in diagnosis.

2. Local Spread. In late cases there is infiltration of the scrotal skin, sometimes associated with fungation. Spread up the cord is shown by the involvement of the lymphatics which may be only found on microscopical examination, or may result in thickening of the cord or the formation of palpable nodules.

3. Distant Lymphatic Spread. (a) Abdominal Glands. Lymphatics lead from the testes to the pre-aortic and lateral aortic glands below the renal vessels. These glands are therefore involved early in cases of testicular tumour, and an abdominal mass was present in a fifth of the cases in this series. Such a mass may cause abdominal or lumbar pain or may, if large enough, produce obstructive symptoms suggesting a carcinoma of the colon or, by involving the ureter, cause first hydronephrosis and later suppression of the function of one or both kidneys. It is often very difficult to palpate a glandular mass in the abdomen of a muscular young man, and examination under anaesthesia is always advisable in such cases, while an intravenous pyelogram is also of value as a routine messure.

(b) Involvement of Other Lymph Glands. The iliac or pre-sacral glands may be directly involved from the primary tumour, but such involvement is rare unless the abdominal or inguinal glands are already extensively involved. The inguinal glands are also rarely affected unless the primary growth is very advanced and has extended through the coverings of the testis, or in cases where the wound has been contaminated at operation and a residual growth remains in the scrotum or inguinal region.

(c) Changes in the Second Testicle. (I) A second primary growth is possible but is a rare occurrence. $^{7}$ (2) An advanced primary growth may involve the second testicle by direct extension. (3) Following involvement of the abdominal lymphatics, a secondary deposit may occur by retrograde lymphatic spread to the contralateral testicle. (4) In widespread disease blood stream metastasis may occur. (5) A varicocoele may de- velop in the left testicle as a result of the presence of a mass of abdominal glands.

(d) Extra-Abdominal Spread. (1) Lymphati spread. There may be enlargement of the supra들 clavicular or axillary glands, or X-rays may shows. mediastinal involvemeñt. (2) Blood stream metass stasis. The most common metastases occur in the parenchyma of the lungs where X-rays show multiple rounded shadows (Fig. 5). Less com $\frac{\overline{\bar{s}}}{\overline{6}}$ monly deposits occur in the bones, subcutaneous tissues, liver and other organs.

\section{Treatment of Testicular Tumours General Principles}

In the present state of our knowledge malignanब disease, in most cases, can be cured only by the complete surgical removal of all malignant cells? or by their complete destruction by X-rays ofi by $\gamma$-radiation. Treatment, therefore, depends oi the 'block' removal of the growth, efferent lym $\vec{v}$ phatics and involved glands together with a margin of normal tissue, or in the adequate irradiation of the same volume of tissue. Since both seminoma and teratoma are very malignant growths which tend to metastasize early, it must always be as sumed that lymphatic spread has extended for $a \overline{0}$ least one stage beyond the area clinically involved. This means that treatment of an early neoplasiff apparently localized to the testis includes remosip or irradiation of the testicular lymphatics anceof the abdominal lymph glands while, theoreticafty if the abdominal glands are involved treatmen should also be given to the mediastinum and to the supraclavicular glands-in practice, as we sha $\frac{1}{8}$ see, the volume of tissue to be irradiated ist limited by the general reaction of the patient.

\section{Methods of Treatment Available}

These tumours may be treated by surgery or by radiotherapy alone, or by a combination of both. methods. The method chosen depends on the stage of the disease, its surgical accessibility and operability, the radiosensitivity of the neoplasm and on the general reaction of the patierit to irradiation.

1. Surgical Methods. Simple and Radical O를. chidectomy.

Simple orchidectomy is the treatment of choiee for the primary tumour. This operation should always be performed through an inguinal incision, the cord should be divided at the internal ring and the testis and cord should be removed in one piece, care being taken to avoid contamination of the scrotum or wound with neoplastic cells. This minor operation provides the simplest and mosp rapid method of treating the primary tumour and has certain added advantages. The diagnosis 
thus completely established and from the histology of the neoplasm its radiosensitivity can be judgedof importance in planning further treatment-and also the prognosis of the patient. Providing that removal is complete, it also renders unnecessary any subsequent irradiation of the scrotum itself and therefore the risk of irradiating the remaining testis and producing sterility.

Radical orchidectomy includes the removal of the lymphatics accompanying the testicular vein and of the regional pre-aortic and lateral aortic glands. This operation was not attended by a high mortality, ${ }^{\circ}$ but adequate dissection of the glands was not always possible. A great improvement in results has been achieved by a combination of simple orchidectomy with irradiation of the lymphatics and of the inguinal, iliac and aortic glands with deep X-rays, a procedure which has now supplanted the radical operation. A case can still be made for the use of this operation in the treatment of early cases of radio-resistant teratoma, but in general there is no doubt that the results of treatment have been greatly improved since the introduction of the combined method as a routine treatment.

\section{Radiotherapy}

The response to radiation varies greatly in different tumours, and while a seminoma responds quickly to radiation, some teratomata are more resistant. The amount of radiation which can be given to any patient is limited by the general reaction of the patient and the effect produced on the normal tissues surrounding the neoplastic cells. The general reaction varies with site and the total volume of tissue to be irradiated, and in these cases this volume of tissue comprises a large proportion of the abdomen, irradiation of which usually tends to cause radiation 'sickness.' The vertebrae are also irradiated, the effect on the marrow sometimes producing a severe fall in the white cell count. These general reactions limit the total quantity of radiation which can be given and the rate at which it is administered and are of far greater importance than the reactions of the normal tissue directly surrounding the tumour cells and of the skin. The effect of this general reaction is such that although an adequate dosage can be administered to destroy the radiosensitive seminoma, we cannot deal so adequately with the relatively insensitive teratoma-a fact well illustrated by the survival figures of the two diseases.

This general reaction also limits our treatment of Stage 3 cases where, theoretically, mediastinal and supraclavicular glands should also be irradiated. In practice the general reaction makes it impossible to administer an adequate quantity of radiation to all areas and it is therefore our usual practice to irradiate the abdomen to a satisfactorily high dosage and to give further treatment only should signs of recurrence appear elsewhere.

Patients may not attend for treatment until metastases are already present in the lungs. In such cases treatment must be given to the whole trunk and the general reaction following the irradiation of such a large volume limits the dosage severely. Even so, there are occasional cases where the radiosensitivity is so great that all lesions will disappear-at least for many months or even years-and therefore treatment should be instituted with a view to ascertaining the radiosensitivity of the tumour and sa of identifying the patients who can still be benefited. In other cases lung metastases develop months or years after the completion of the first treatment. In such cases only the chest requires treatment and the general reaction is therefore less severe and a more adequate dosage can be employed. In this series alone three patients suffering from seminoma are well and without clinical or radiological evidence of metastases several years after the treatment of multiple pulmonary metastases. The results in teratoma are far less encouraging, but here again a trial should be made of the radiosensitivity of the lesion before deciding that all treatment must be abandoned. The following combinations of treatment is used in different stages of the disease :-

Stage 1.-Limited to testis. Orchidectomy with division of cord at internal ring, followed by deep X-ray treatment to inguinal wound and glands, iliac glands and aortic glands up to the level of the diaphragm.

Stage ra.-Patients in whom there is residual neoplasm in the scrotum following orchidectomy. As Stage I, but with the addition of irradiation of the affected side of the scrotum, the contralateral testis being shielded as much as possible.

Stage 2. - Involvement of inguinal or iliac glands. As Stage 1 .

Stage 3.-Patients with clinical involvement of the abdominal glands. As Stage I but followed if possible by irradiation of the mediastinum and supraclavicular glands (rarely possible owing to general reactions).

Stage 4.-Distant metastases by lymphatics or blood stream. (a) 'Curative' method of irradiation of whole of tissue involved, i.e. whole trunk (rarely possible). (b) 'Palliative' irradiation of metastases producing symptoms.

\section{Results of Treatment}

The results of the treatment of testicular tumours improved greatly following the introduction of the combination of surgery and deep $\mathrm{X}$-ray treatment. The results of treatment depend on the type of tumour, its malignancy and 
TABLE 6

Results of Treatment of Seminoma and Teratoma

\begin{tabular}{|c|c|c|c|c|c|}
\hline \multicolumn{6}{|c|}{ All new cases treated I $929-50$} \\
\hline \multirow[t]{2}{*}{$\begin{array}{l}\text { Stage I } \\
\text { Stage } 2 \\
\text { Stage 3 } \\
\text { Stage 4 } \\
\end{array}$} & \multicolumn{4}{|c|}{$\begin{array}{l}\text { Disease limited to testis. } \\
\text { Involvement of inguinal/iliac } \\
\text { Involvement of aortic glands. } \\
\text { Distant metastases. }\end{array}$} & ads. \\
\hline & Total & Stage I & $\begin{array}{l}\text { Stage } \\
2\end{array}$ & $\begin{array}{c}\text { Stage } \\
3\end{array}$ & $\begin{array}{c}\text { Stage } \\
4\end{array}$ \\
\hline $\begin{array}{l}\text { Seminoma } \\
\text { Teratoma }\end{array}$ & $\begin{array}{r}107 \\
53\end{array}$ & $\begin{array}{l}87(8 \mathrm{r} .3 \%) \\
39(73.6 \%)\end{array}$ & $\begin{array}{l}4 \\
0\end{array}$ & $\begin{array}{r}10 \\
7\end{array}$ & $\begin{array}{l}6 \\
7\end{array}$ \\
\hline
\end{tabular}

TABLE 7

Results of Treatment $1929-48$

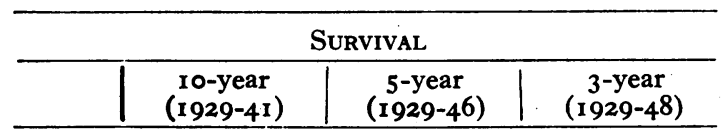

\begin{tabular}{l|c|c|c}
\multicolumn{3}{c}{ Seminoma } \\
\hline All cases & $* 21 / 38(55.3 \%)$ & $* 52 / 77(67.5 \%)$ & $+66 / 92(71.7 \%)$ \\
Stage I & $21 / 29(72.4 \%)$ & $49 / 61(80.3 \%)$ & $60 / 73(82.2 \%)$ \\
Stage 2 & $0 / 2$ & $1 / 3$ & $2 / 4$ \\
Stage 3 & $0 / 4$ & $1 / 7$ & $3 / 9$ \\
Stage 4 & $0 / 3$ & $1 / 6$ & $1 / 6$ \\
\hline
\end{tabular}

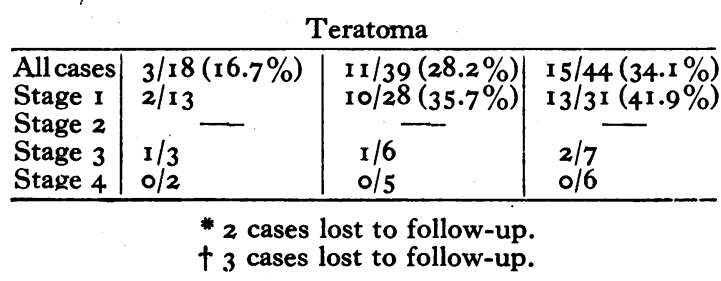

radiosensitivity, and on the stage of the disease. A highly malignant tumour will metastasize very early and so present usually at a later stage however short the history. Also, while usually radiosensitive, the speed of the advance of the condition is so great that the prognosis is usually very badthis type of growth is described by Gordon-Taylor and Till ${ }^{8}$ as ' hurricane.' The majority of teratoma are far less radiosensitive than are seminoma, and therefore the results of treatment are worse; among the teratomata the highly malignant chorionepithelioma is usually more radiosensitive than any other malignant tumour of the testis, but again the malignancy is so great that the re- sults are far worse than those obtained by the treatment of less sensitive but also less malignan forms of the disease (Tables 6 and 7, Fig. 12). $\stackrel{\mathbb{Q}}{\perp}$

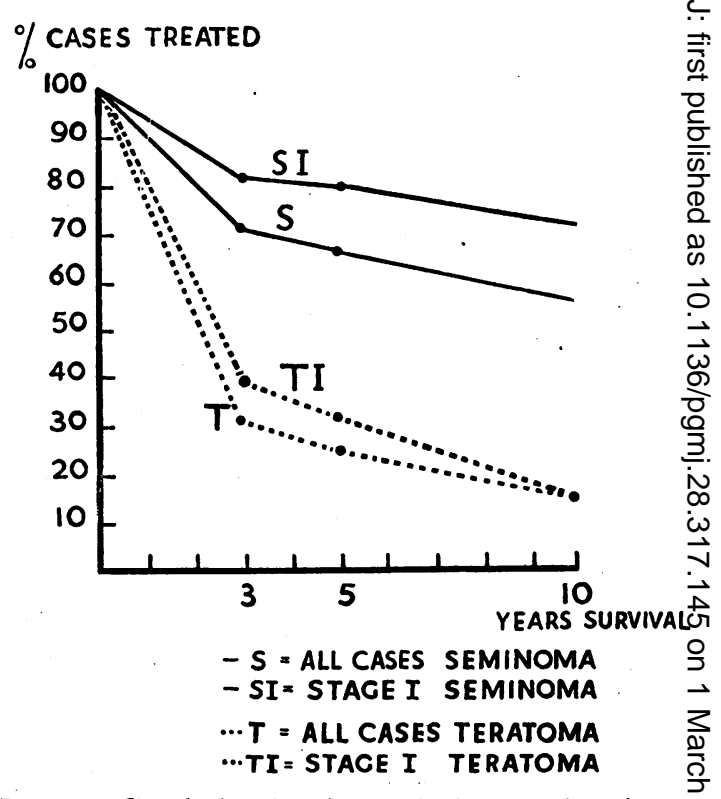

FiG. 1 2.-Graph showing the survival states of semingma and teratoma, following treatment.

\section{Summary}

A brief account is given of the pathology surgical anatomy and biochemistry of malignant tumours of the testicle. The clinical features and treatment are described and illustrated by th $\mathbb{B}$ clinical histories and results of treatment of series of 166 cases treated at the Middlesex Hospital between 1929 and 1951 .

\section{Acknowledgments}

We have pleasure in recording our thanks to. Prof. B. W. Windeyer for permission to publislo material from departmental records. Figs. I to 4 were taken from specimens from the Middlesex Hospital Museum, and for permission to publish them we are indebted to Prof. R. W. Scarff. The clinical and pathological photographs were taken by Mr. M. Turney of the Middlesex Hospitat. Photographic Department.

\section{REFERENCES}

I. BLOOM, H. J. G. (1950), Brit. F. Cancer, 4, 259, 347.

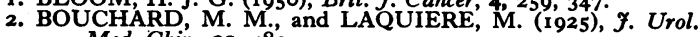
Med. Chir., $20,483$.

3. CAIRNS, SIR HUGH (1926), Lancet, i, 845.

4. CAMPBELL, H. E. (1942), Arch. Surg., 44, 353.

5. CHEVASSU, MAURICE' (1906), 'Tumeurs de Testicule,' Paris.

6. EWING, J. (1911), Surg. Gynec. Obstet., 12, 230.

7. GORDON-TAYLOR, SIR GORDON, and WYNDHAM, NORMAN R. (I947), Brit. F. Surg., 35, 6.

8. GORDON-TAYLOR, SIR GORDON, and TILL, A. S. (1938), Brit. $\boldsymbol{\jmath}$. Urol., 10, 33.
9. BAILEY, H. (1936), 'Diseases of the Testicle,' London, H. Kब Lewis.

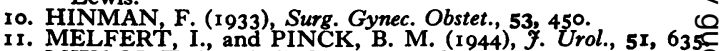

I1. MELFERT, I., and PINCK, B. M. (1944), $尹$. Urol., 51, 635

13. MYATA (1913), Arch. f. Clin. Chir. C.I., 426 .

14. PROSSER; T. M. (0000), Brit. F. Surg., 38, 1.52.

15. REA C. E. (1031), Amer, F. Cancer, 15, 2646. T

16. WILLIS, R. A.' (1948), 'Pathology of Tumours,' London $\bar{D}$

Butterworth.
17. WINSBURY-WHITE, H. D. (1948), 'Textbook of Genito@ Urinary Surg.,' Edinburgh, E. \& S. Livingstone. 